Gut, 1973, 14, 701-710

\title{
Cell kinetics in flat (avillous) mucosa of the human small intestine
}

\author{
NICHOLAS WRIGHT, ALEXANDER WATSON, ADRIAN MORLEY, DAVID \\ APPLETON, AND JANET MARKS
}

From the Departments of Pathology, Medical Statistics, and Dermatology, University of Newcastle upon Tyne, England

SUMMARY A new method for the analysis of small-intestinal crypt-cell kinetics using routine peroral diagnostic biopsies is described. Untreated patients with childhood and adult coeliac disease and adults with the gluten-sensitive enteropathy of dermatitis herpetiformis were studied, together with groups of adult and childhood controls. In the classical flat avillous mucosae the increase in crypt size was found to be three-dimensional. The number of proliferating cells per crypt was shown to be markedly increased, and an even greater rise in the crypt-cell production rate was demonstrated. A significant increase in the mitotic index was also confirmed in the avillous mucosae.

On the basis of these findings it is suggested that the characteristic crypt morphology in glutensensitive enteropathy can be explained as an adjustment to accommodate the expanded mass of proliferating and maturing cells necessary to support the augmented cell production rate. We may speculate that this in turn is a response to a pathologically rapid loss of cells from the mucosal surface.

With the introduction of peroral biopsy of the small bowel, morphological assessment of the mucosa became a routine investigatory procedure. It was soon confirmed (Bertalanffy and Nagy, 1961) that the rapid epithelial turnover already recognized in animals also occurred in the normal human small bowel. Despite early indications that a severe disturbance of mucosal dynamics was present in coeliac disease (Padykula, Strauss, Ladman, and Gardner, 1961), progress in characterizing this important aspect has been haltingly slow.

Indirect observations have certainly suggested that the rate of mucosal-cell loss in coeliac disease is greatly increased (Pink, Croft, and Creamer, 1970), and an obvious corollary is that the rate of cell production must be similarly enhanced. Padykula et al (1961) reported an increased mitotic index in coeliac disease, an observation confirmed by Yardley, Bayless, Norton, and Hendrix (1962). On the other hand Creamer (1962) found a low mitotic index in the crypts of coeliac disease compared with normal crypts, and in one patient demonstrated a slower cell migration rate. These findings were interpreted as indicating a prolonged turnover time with perhaps a defective maturation sequence.

Received for publication 16 May 1973.
Booth (1970) in a recent review considered that the bulk of the evidence was in favour of a hyperproliferative state in coeliac disease, and suggested that the characteristic changes in crypt morphology were a direct consequence of 'enteroblastic hyperplasia' compensating for excessive loss of surface enterocytes. This hypothesis, that the characteristic changes in crypt morphology result from an induced change in the functional activity of the crypts, can only be substantiated by detailed analysis of the organization of cell renewal in the flat avillous mucosae of coeliac disease. A factor which should also be taken into account and which may explain some previous discrepancies is the possible heterogeneity of coeliac disease. For example, is the kinetic disturbance similar in the childhood and adult syndromes, and what is the relation of these to the glutensensitive enteropathy of dermatitis herpetiformis?

Hitherto there has been a lack of safe techniques of sufficient sophistication to provide information about the more important proliferative parameters established in experimental animals. We have evolved a technique by which useful data can be obtained from routine peroral small bowel biopsies and have studied cell kinetics in patients with childhood and adult coeliac disease, in cases of dermatitis herpetiformis with a flat mucosa, and in appropriate controls. 


\section{Materials and Methods}

BIOPSY SPECIMENS

All mucosal specimens studied were obtained by peroral biopsy of the duodeno-jejunal region using a modified Crosby capsule. Most biopsies were taken at about the middle of the day in an attempt to exclude diurnal variation of proliferative indices (Sigdestad, Banman, and Lesher, 1969). Biopsies were orientated under the stereomicroscope, spread on glass, and immediately fixed in 10\% neutral buffered formol saline. To improve nuclear staining specimens were postfixed in a solution of mercuric chloride. Specimens were then embedded in paraffin wax and serially sectioned at a thickness of $3 \mu \mathrm{m}$. Sections for analysis were stained with Harris's haematoxylin.

\section{PATIENTS}

Two series of control patients were studied. The adult controls comprised 75 persons, males and females, over the age of 20 . The childhood controls were 10 in number, all below 7 years of age. Inclusion in the control groups was dependent purely on the morphological appearance of the small bowel biopsy and was not related to the patient's clinical history. Such control biopsies were those showing finger-shaped or leaf-shaped villi on stereomicroscopy and an absence of pathological features on histological examination. Biopsies showing convolutions or protoconvolutions were excluded even in the absence of any significant histological abnormality. The patients with a flat avillous mucosa totalled 62 , and comprised 13 patients with adult coeliac disease (ACD), 20 adult patients with dermatitis herpetiformis (DH), and 29 patients with childhood coeliac disease (CCD).

\section{CRYPT ANALYSIS}

In virtually all cases 30 crypts were selected for examination but in a few instances, because of poor orientation or inadequate size of the specimen, less than 30 crypts were available. Only complete axial crypt sections were analysed, ie, those in which the base, middle, and mouth of the crypt were all in the plane of section. Care was taken to ensure that each crypt was analysed only once. The counting techniques of Cairnie, Lamerton, and Steel (1965a) were used throughout. The identity of the sections was unknown to the observer. In each crypt the left hand column of cells was numbered, counting from the bottom upwards to the crypt-villus junction; this is referred to as the 'crypt column', illustrated in figure 1. The positions in the crypt column of cells in mitosis were recorded. A mitosis situated midway

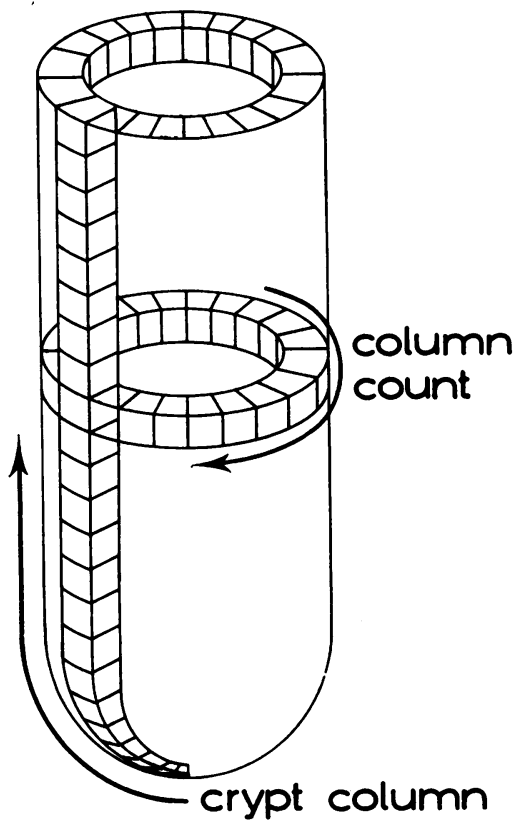

Fig 1 Diagrammatic representation of the column count and crypt column.

between the right and left crypt columns was counted as a half (Cairnie et al, 1965a).

In any sample of small intestinal crypts both in man and in animals considerable variation is found in the height of the crypt columns (Cairnie et al, 1965a; Wright, Morley, and Appleton, 1972a and b) and in calculating the mitotic index as a function of cell position in the crypt column such variation should be taken into account. Plotting the variation in mitotic index with cell position gives a mitotic index distribution curve. Figure 2 illustrates the method of construction. In normal animals Cairnie and Bentley (1967) found differences in the distribution of tritiated thymidine-labelled cells in short and long crypts according to whether the positions of cells were taken relative to the top or bottom of the crypt; clearly the same argument applies to the distribution of mitoses.

In order to compensate for this variation, the data were processed by an ALGOL computer program run on an IBM 360/67 computer. The details of the method are given elsewhere (Wright et al, 1972a and b), but is based on the hypothesis that a crypt cell's location is best described not by its position relative to the top or bottom of the crypt but by its position relative to the total number of cells in the crypt column. Consequently each crypt is projected onto a large standard crypt for the calculation of the mitotic index at each cell position, and then onto a 


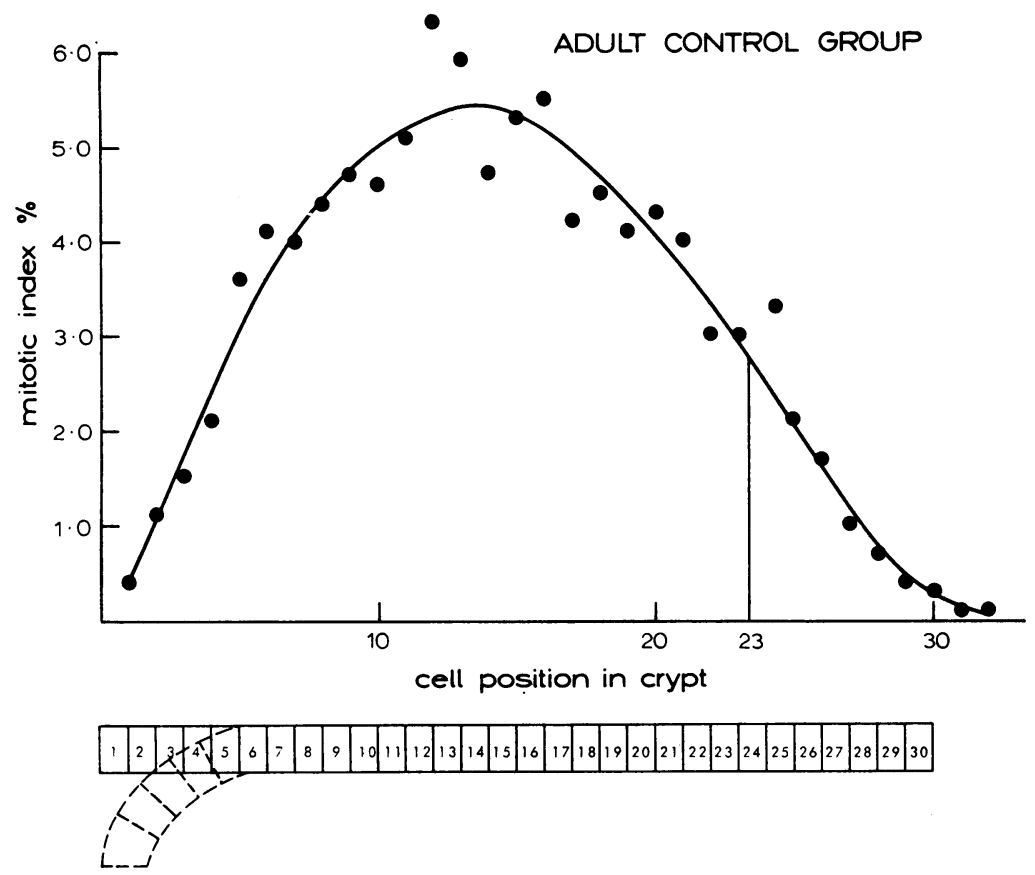

Fig 2 The method of construction of a mitotic index distribution curve. The crypt column is shown horizontally to illustrate that the individual points on the graph represent mitotic indices at each cell position.

crypt whose size is the mean for the group analysed. This manoeuvre reduces the differencein mitoticindex distribution in long and short crypts from the same sample.

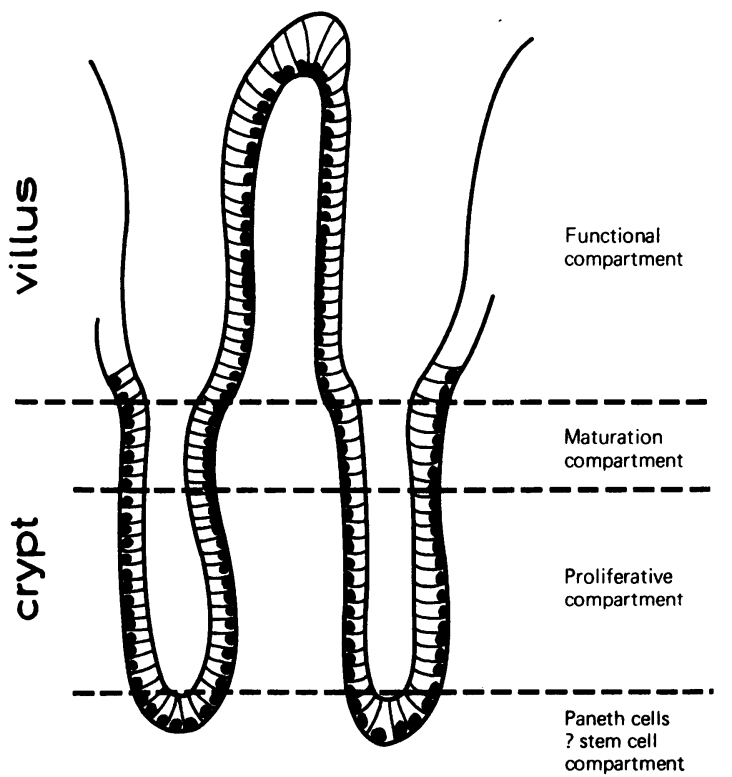

Fig 3 Diagrammatic representation of the kinetic compartments in the small bowel mucosa.
In the crypts two morphometric parameters were measured, and these are illustrated in figure 1 . The length of the crypt column in terms of cell numbers was measured in the analysis of the axially sectioned crypts described above. Afterwards such material as remained in the blocks was reorientated and sectioned transversely through the crypts for measurement of the column count. The column count is the number of cells in a crypt cross section, and is equal to the number of crypt columns in the crypt. This measurement involved counts carried out on 100 crypt cross sections in each specimen analysed.

THE KINETIC COMPARTMENTS

The small bowel mucosa can be divided into several kinetic compartments (fig 3), each fulfilling a particular role in cell production. Most cell production occurs in the lower portion of the crypt, called the proliferative compartment. Moving upwards, cells lose the ability to divide and pass into the maturation compartment. From here differentiated cells move into the functional compartment on the surface of the villus. Recently a further compartment has been delineated, the stem-cell compartment, which is located at the base of the crypt and supplies cells to the proliferative compartment (Lamerton, 1972; Wright et al, 1972b).

The changes in the sizes of these compartments which occur in coeliac disease may be important in 
understanding the evolution of the characteristic morphology. The method of analysis described in this paper allows comparative estimates of the proliferative and maturation compartment sizes in terms of the fractional length of the crypt column. Perhaps a more realistic measure of these compartments lies in the actual number of cells which they contain. Wimber and Lamerton (1963) have shown that the product of the column count and the crypt column gives a reliable estimate of the total crypt population. Knowledge of the fraction of the crypt occupied by a particular compartment then allows calculation of the total number of cells present in that compartment.

Inspection of fig 3 shows that a critically important region of the crypt is the transition zone from the proliferative to the maturation compartment, called the 'cut-off region' (Cairnie et al, 1965b). Changes in the position of this cut-off region will control the size of the proliferative compartment, and therefore the growth fraction, ie, the proportion of crypt cells actually dividing.

\section{Results and Interpretation}

The distribution in the height of the crypt columns is shown for the control groups in fig 4 and the mean values in table I. A slight increase in both column height and column count is apparent in the childhood controls compared with adults, and the estimate of the total crypt population obtained from these two parameters is similarly increased. The column height distributions for the flat mucosae of childhood and adult coeliac disease and dermatitis herpetiformis are shown in fig 5, and mean values of both morphometric parameters are also given in table I. In each of the three groups there is marked lengthening of the crypt column, and the lengths attained are not

\begin{tabular}{|c|c|c|c|}
\hline & $\begin{array}{l}\text { Crypt Column } \\
\text { (cells) }\end{array}$ & $\begin{array}{l}\text { Column Count } \\
\text { (cells) }\end{array}$ & $\begin{array}{l}\text { Total Cells } \\
\text { in Crypt }\end{array}$ \\
\hline $\begin{array}{l}\text { Adult controls } \\
\text { Adult coeliac disease } \\
\text { Dermatitis herpetiformis } \\
\text { Childhood controls } \\
\text { Childhood coeliac disease }\end{array}$ & $\begin{array}{l}31.9 \pm 0.1 \\
74 \cdot 1 \pm 0.6 \\
75 \cdot 7 \pm 0.6 \\
34.4 \pm 0.3 \\
74.9 \pm 0.6\end{array}$ & $\begin{array}{l}24 \cdot 5 \pm 0 \cdot 2 \\
41 \cdot 2 \pm 0 \cdot 3 \\
35 \cdot 7 \pm 0 \cdot 3 \\
25 \cdot 3 \pm 0 \cdot 2 \\
35 \cdot 3 \pm 0 \cdot 5\end{array}$ & $\begin{array}{r}780 \\
3050 \\
2700 \\
870 \\
2640\end{array}$ \\
\hline
\end{tabular}

Table I Morphometric parameters in control and flat mucosae with standard errors

significantly different. However, the column counts in the adult coeliac disease group show a large increase over that in both childhood coeliac disease and dermatitis herpetiformis, the values in the latter two groups being not significantly different. All three groups show large increases in column count over the control values. The estimates of total crypt-cell populations likewise show a three- to fourfold increase compared with the controls. Crypt enlargement in coeliac disease is therefore three-dimensional, with the crypts in mucosae of adult coeliac disease containing the most cells.

In each group the mitotic index $\left(\mathrm{I}_{\mathrm{m}}\right)$ was calculated for each cell position and mitotic index distribution curves are shown for the control groups in fig 6 and for the flat mucosae in figure 7. The adult control curve shows low $I_{m}$ values in the lower cell positions rising from below $0.5 \%$ at cell position 1 to reach a peak of over $5 \%$ between positions $10-15$. This peak is followed by a slow return to low values as the maturation compartment is reached.

The growth fraction can be calculated approximately from the mitotic index distribution curve. It is evident that a growth fraction calculated for the whole crypt represents the fraction of the crypt population that is in the proliferative compartment. This
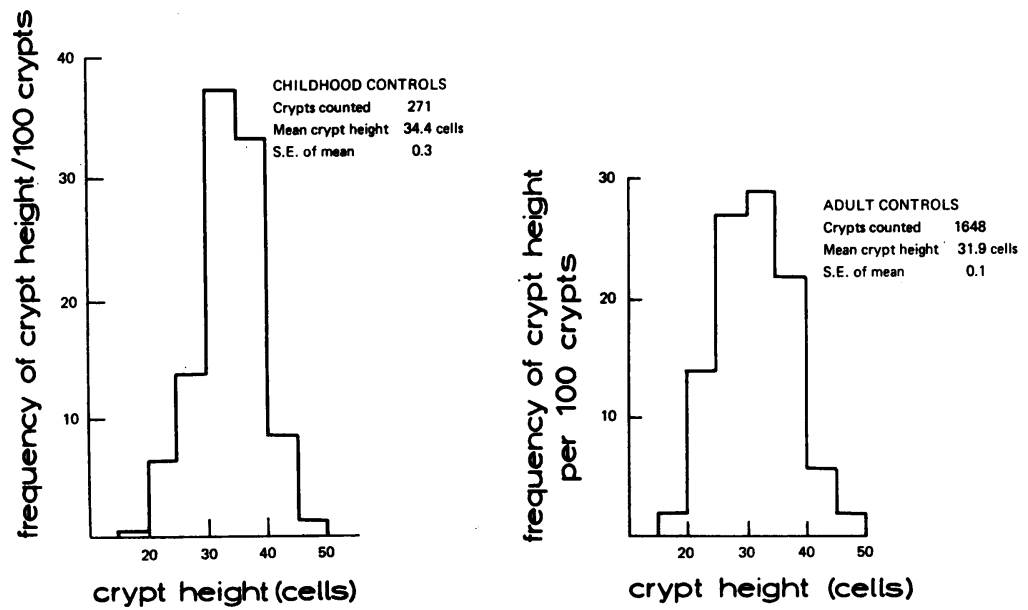

Fig 4 The distribution in the height of the crypt columns in the control groups. 


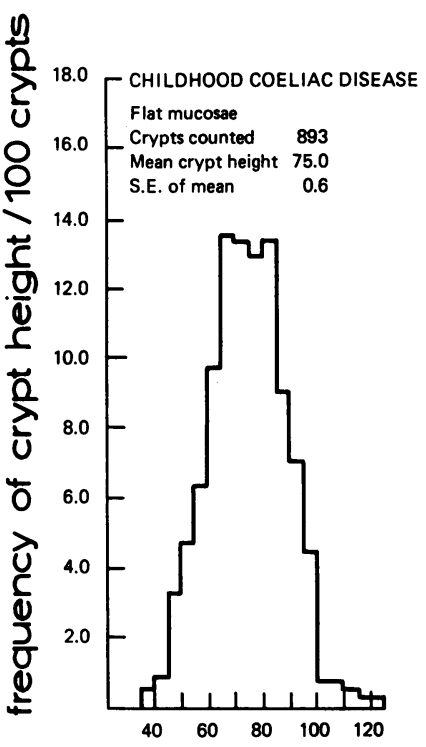

crypt height (cells)
ADULT COELIAC DISEASE

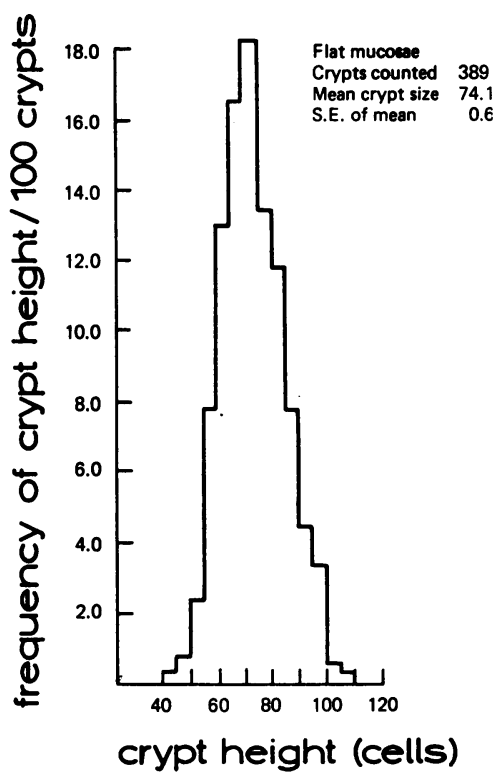

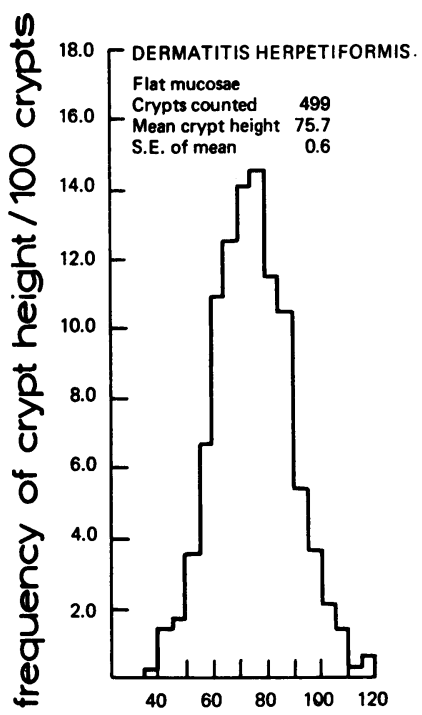

crypt height (cells)

Fig 5 The distribution in the height of the crypt columns in the flat mucosae.

is the region over which mitoses are observed and it may be considered to end at approximately the cell position where the $I_{m}$ falls to $50 \%$ of its maximum or peak value (Cleaver, 1967). The maturation compartment then becomes those cells above the cell position where the $I_{m}$ falls to $50 \%$ of the maximum value.

In the mitotic index distribution curve for the adult controls the $50 \%$ peak value is found at cell position 23 , and the growth fraction $\left(I_{p}\right)$ for the whole crypt may be taken as the ratio of the proliferative compartment size of 23 cells to the total cells in the crypt column, ie, $23 / 32$, or 0.72 . The childhood controls show an $I_{m}$ in the lower cell positions greater than in the adult controls. This bottom end of the crypt is the portion occupied by the stem cells and these findings may reflect kinetic differences in this compartment between these two groups. The curve then rises to reach a slightly higher peak of over $6 \%$ between cell positions 10 and 15 , before falling again as in the adult controls. The $50 \%$ peak value is again at cell position 23 , but since the crypts are longer the growth fraction is $23 / 34$ or 0.68 , slightly lower than in the adult controls.

All the flat mucosae show large differences in $I_{m}$ distribution compared with the controls. In adult coeliac disease, high values of around $2 \%$ are apparent in the stem-cell compartment followed by a sharp rise to reach a maximum $I_{m}$ of $11.5 \%$ at between cell positions 15 and 20. A steep fall then occurs, with the $50 \%$ peak value at position 41 , giving an $I_{p}$ estimate of 0.55 . The $I_{m}$ distribution curve of dermatitis herpetiformis shows a similar configuration to that of adult coeliac disease with several minor differences. $I_{m}$ in the stem cell compartment is lower even than in the adult controls. The
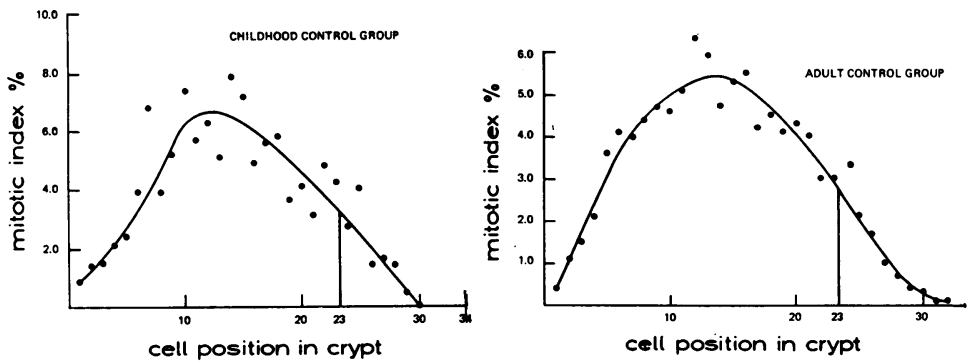

Fig 6 Mitotic index distribution curves for the control groups. 

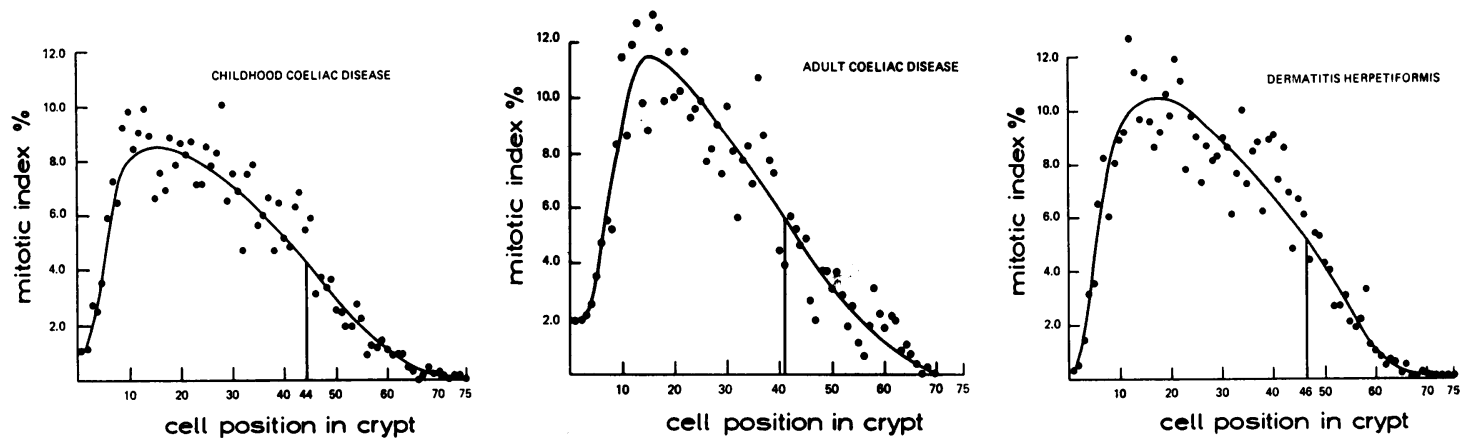

Fig 7 Mitotic index distribution curves for the flat mucosae.

peak value is somewhat less than in adult coeliac disease, realizing $10.0 \%$ between positions 10 and 23 . The trailing edge of the curve is less steep than in adult coeliac disease, with a $50 \%$ peak value of 46 giving an $I_{p}$ estimate of $0 \cdot 60$.

Childhood coeliac disease shows an $I_{m}$ in the stem cell compartment similar to the childhood controls. However a sharp rise then occurs to reach a maximum $I_{m}$ of over $8 \%$ between cell positions 12 and 23 . The $50 \%$ peak value is 44 and the $I_{p} 0 \cdot 59$. As mentioned above, a growth fraction calculated for the whole crypt represents the fraction of the crypt population that is in the proliferative compartment. The remaining cells can be considered to have left the cell cycle and to be occupying the maturation compartment. The compartment sizes measured from the $I_{m}$ distribution curves are summarized in table II. Although minor differences are apparent between the three groups of flat mucosae an absolute increase in proliferative compartment size (in terms of cells) is evident compared with the control values. On the other hand there is a relative reduction in proliferative compartment size compared with the controls when the parameter is expressed as a fraction of the total crypt column. In the case of the maturation compartment in each group both an absolute and a relative increase in size is found in the flat mucosae compared with the control values.
From estimates of the growth fraction, and knowing the number of cells per crypt, it is possible to arrive at a value for the total number of proliferating cells per crypt (table II). As compared with controls, a threefold increase in proliferating cells per crypt can be demonstrated in adultcoeliac disease and dermatitis herpetiformis, while in childhood coeliac disease the increase is a little less than threefold. Despite the finding of a relative reduction in proliferative compartment size as measured from $I_{m}$ distribution curves in the coeliac groups, the three-dimensional increase in crypt size nevertheless entails this large increase in proliferating cells per crypt. It should be noted that although the crypt population in adult coeliac disease is greater than in dermatitis herpetiformis the number of proliferating cells per crypt is similar because of the larger $I_{p}$ in dermatitis herpetiformis.

The value obtained for the $I_{m}$ expressed as a percentage of all crypt cells counted constitutes the crude mitotic index (table III). Each flat mucosa group shows a significant increase over the value in its respective control group. The mitotic index is directly dependent upon the growth fraction, and particularly in circumstances such as the present, when variation in $I_{p}$ has been shown between the contrasted groups, should be expressed as a percentage of the proliferating population. When this is

\begin{tabular}{|c|c|c|c|c|c|}
\hline & $\begin{array}{l}\text { Proliferative } \\
\text { Compartment Column } \\
\text { Size(cells) }\end{array}$ & $\begin{array}{l}\text { Maturation } \\
\text { Compartment Column } \\
\text { Size }(\text { cells })\end{array}$ & Growth Fraction & $\begin{array}{l}\text { Total Number of } \\
\text { Proliferating Cells } \\
\text { per Crypt }\end{array}$ & $\begin{array}{l}\text { Total Number of } \\
\text { Maturing Cells per } \\
\text { Crypt }\end{array}$ \\
\hline
\end{tabular}

Table II Compartment sizes and proliferating populations in control and fat mucosae

In this table the proliferative compartment includes the stem cells. 


\begin{tabular}{lll}
\hline & $\begin{array}{l}\text { Crude Mitotic } \\
\text { Index (\%) }\end{array}$ & $\begin{array}{l}\text { Corrected Mitotic } \\
\text { Index (\%) }\end{array}$ \\
\hline Adult controls & 3.05 & $4 \cdot 23$ \\
Adult coeliac disease & $5 \cdot 22$ & $9 \cdot 49$ \\
Dermatitis herpetiformis & $5 \cdot 46$ & $9 \cdot 10$ \\
Childhood controls & 3.47 & $5 \cdot 10$ \\
Childhood coeliac disease & $4 \cdot 58$ & $7 \cdot 77$ \\
\hline
\end{tabular}

Table III Mitotic indices in control and flat mucosae

${ }^{1}$ See text.

done, the 'corrected' mitotic indices indicate even larger differences between the flat mucosa groups and their controls; in the case of adult coeliac disease and dermatitis herpetiformis the corrected mitotic index is more than double the adult control value. Both these conditions show significantly higher mitotic indices than childhood coeliac disease $(\mathrm{P}<$ 0.001 ), but there is no significant difference between adult coeliac disease and dermatitis herpetiformis.

If it is assumed that the duration of mitosis does not differ in the groups studied, and if we further assume that this parameter is one hr, then comparative values for the rate of cell production, the migration rate, and the transit times can be calculated. This assumption is defended in the discussion, and has been explored in subsequent investigations (Wright, Watson, Morley, Appleton, Marks, and Douglas, 1973).

The birth rate $\left(k_{b}\right)$, or rate of cell production by cell division alone, can be calculated from the ratio of the mitotic index $\left(I_{m}\right)$ to the mitotic duration $\left(t_{m}\right)$.

$$
\mathbf{k}_{\mathbf{b}}=\frac{\mathbf{I}_{\mathbf{m}}}{\mathbf{t}_{\mathbf{m}}}
$$

If the birth rate is calculated for each cell position and these values are then summated, a cumulative birth rate curve is obtained (Cairnie et al, 1965a;
Wright et al, 1972a and b) and the efflux past any cell position is equal to the sum of the birth rates up to that position (Cleaver, 1967). Furthermore, the maximum birth rate attained is equal to the total efflux from the top of the crypt column, and is also equal to the migration rate at any point above which cell proliferation has ceased, since the maturation compartment is a simple transit compartment.

Cumulative birth rate curves are shown for the controls in fig 8 and for the flat mucosae in figure 9. Values for the maximum birth rate attained, or in other words, the migration rate, are shown in table IV. In each coeliac group there is a three- to fourfold increase in migration rate compared with control values, the increase being most prominent in dermatitis herpetiformis and adult coeliac disease. The product of the migration rate and the column count gives an estimate of cell production rate per crypt. (table IV). The adult control group shows a cell production rate of 25 cells per crypt per hour, increased to some 150 cells per hour in adult coeliac disease and hermatitis herpetiformis. The increase in childhood coeliac disease is smaller but nonetheless considerable.

\begin{tabular}{llc}
\hline & $\begin{array}{l}\text { Migration Rate } \\
\text { (cell positions/hour) }\end{array}$ & $\begin{array}{l}\text { Cell Production Rate } \\
\text { (cells/crypt/hour) }\end{array}$ \\
\hline Adult controls & $1 \cdot 0$ & 25 \\
Adult coeliac disease & $3 \cdot 8$ & 155 \\
Dermatitis herpetiformis & $4 \cdot 0$ & 143 \\
Childhood controls & $1 \cdot 2$ & 29 \\
Childhood coeliac disease & $3 \cdot 4$ & 120 \\
\hline
\end{tabular}

Table IV Crypt efflux in control and flat mucosae, assuming a mitotic duration of one $\mathrm{hr}$ in all instances

The transit times through the various compartments can be estimated from the above cumulative birth rate curves by taking the reciprocal of the
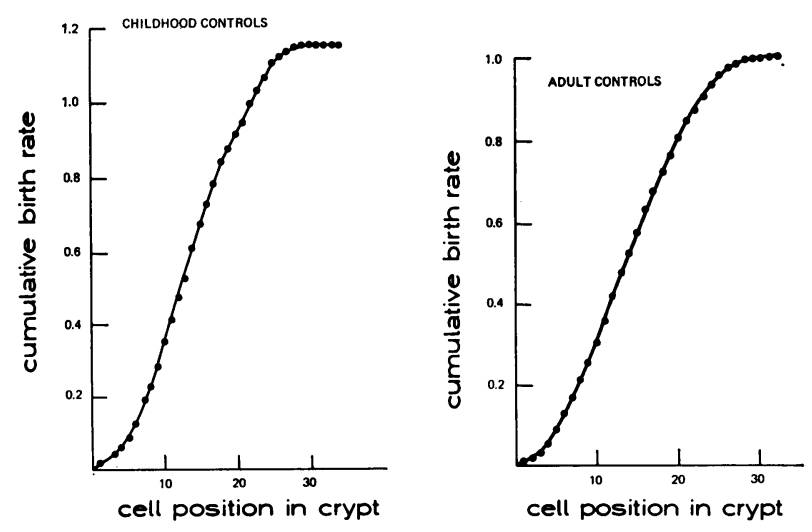

Fig 8 Cumulative birth rate curves for the control groups. 

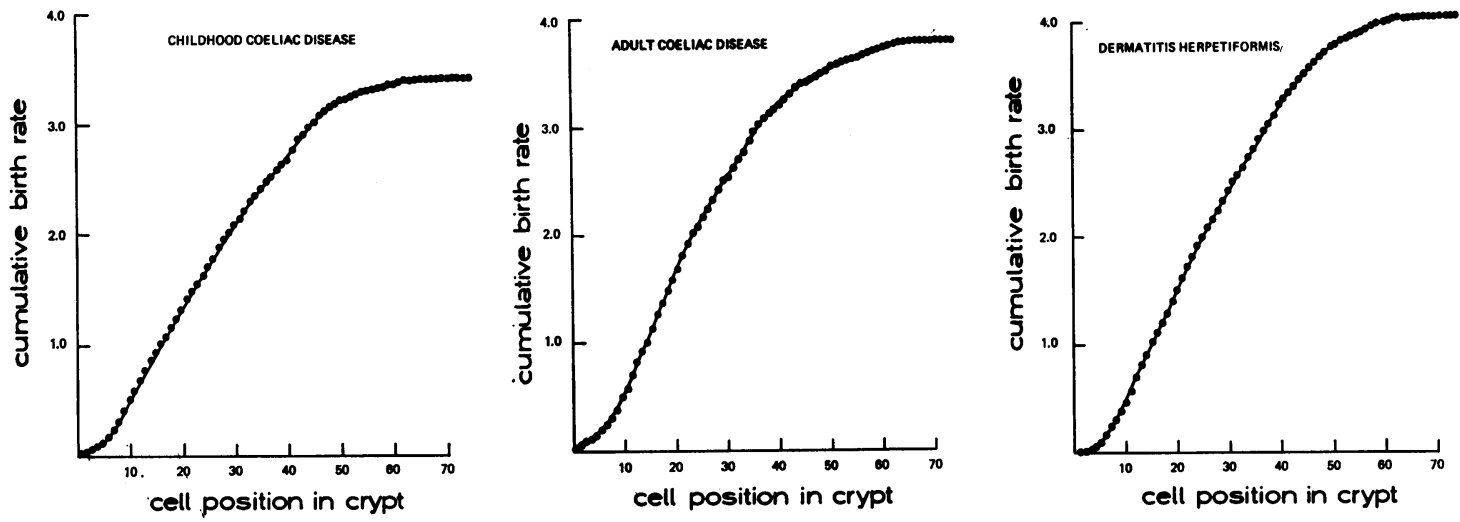

Fig 9 Cumulative birth rate curves for the flat mucosae.

cumulative birth rate at each cell position and summating these values over the relevant portion of the crypt (table V). The problem of defining the size of the stem-cell compartment has been considered by several investigators (Cleaver, 1967; Wright et al, $1972 \mathrm{a}$ and $\mathrm{b})$. In this investigation an arbitrary delineation of this compartment has been made and stem-cells are regarded as occupying those cell positions with a transit time in excess of 10 hours. In effect this places the first five cell positions of the control groups within this compartment, and also the first five cell positions of the flat mucosa groups. Proliferative-compartment transit time is slightly decreased in both adult coeliac disease and dermatitis herpetiformis while maturation-compartment transit time is similar in both. This similarity in proliferative and maturation compartment transit times between the control and coeliac groups is a reflection of the increased migration rate in the elongated crypts of the flat mucosae. In the childhood controls the transit times are somewhat faster than in the adults, but because of the increased migration rate in childhood coeliac disease, transit times in that and in the childhood controls are similar.

\section{Discussion}

The conclusions made possible by this study permit a formalization of current thought on the mechanism of evolution of a flat mucosa in coeliac disease. In the flat mucosae of the three groups of patients with gluten-sensitive enteropathy the crypts have been shown to be increased not only in length but also in girth. There is a large increase in the total crypt population, and in particular the number of proliferating cells per crypt is increased threefold. The total number of maturing cells is even more markedly increased, for example, from 220 in the adult control group to 1370 in adult coeliac disease, a sixfold increase (see table II). This great increase in maturing cells can be thought of as a natural consequence of the increased output from the proliferative compartment, an output which is increased five to sixfold. This enhanced output of cells must be accommodated during maturation in a much enlarged maturation compartment.

The altered crypt morphology in gluten-sensitive enteropathy is therefore a response to the need to accommodate a greatly increased mass of proliferating and maturing cells. These in turn are needed to keep pace with the increased rate of surface cell loss which has been shown in this condition (Pink et al, 1970), and a sequence of compensatory reactions in the crypt can be envisaged. A moderate loss could be made good by upward movement of the "cut-off position' leading to an increase in the growth fraction

\begin{tabular}{llllll}
\hline & \multicolumn{2}{l}{ Transit Times (hours) } & & & \\
\cline { 2 - 6 } & Stem & Proliferative & Maturation & Total & (Total-Stem) \\
\hline Adult controls & 379 & 39 & 8 & 427 & 47 \\
Adult coeliac disease & 124 & 36 & 9 & 170 & 45 \\
Dermatitis herpetiformis & 540 & 33 & 761 & 40 & 43 \\
Childhood controls & 218 & 34 & 8 & 239 & 43 \\
Childhood coeliac disease & 196 & 34 & 8 & 8 & \\
\hline
\end{tabular}

Table V Transit times for control and flat mucosae assuming a mitotic duration of one hr in all instances 
(Wright et al, 1972a). But if this response were insufficient to meet a greater loss the proliferating cell mass could be further increased only by crypt enlargement, and this evidently occurs in three dimensions, with a resulting increase in length and girth of the crypts.

The relatively large numbers of patients analysed in each group, together with the standardized counting techniques, makes the values obtained for the mitotic indices likely to be particularly valuable statistically. It has been established that there is a significant increase in the mitotic index in the flat mucosa of gluten-sensitive enteropathy in accord with the observations of Padykula et al (1961) and Yardley et al (1963). There are, however, certain problems involved in the interpretation of a crude mitotic index, which by itself should not be regarded as a definitive index of proliferative state. It is essential to relate the mitotic index to the proliferating cells only, as the existence of a significant proportion of non-dividing cells will lead to an underestimate of proliferative activity; this is especially important when, as in the present study, comparisons are drawn between cell populations with differing compartmental sizes. When the mitotic index is expressed as a percentage of the proliferating cells only, the increase in the flat mucosa groups then becomes much larger.

The relationship of changes in mitotic index to the rate of cell division (mitotic rate) can be evaluated only if the mitotic duration is known. The increased mitotic indices in the flat mucosa groups reflect an increased rate of cell division only if there is no change in mitotic duration. In the present paper we have assumed that there is no significant change in mitotic duration, and that this parameter is one $\mathrm{hr}$ in all groups. Wright, Watson, Morley, Appleton, Marks, and Douglas (1973) have shown that the mitotic duration in normal human jejunum is about one $\mathrm{hr}$, and using this value we have obtained a migration rate of 1.0 cell positions/hr in the adult controls, which agrees exactly with the value of Lipkin (1965), achieved by direct observation of cells labelled with tritiated thymidine. Wright et al (1973) have shown that the mitotic duration in flat mucosae is also close to one hour.

It is therefore apparent that crypt-cell migration rate is increased in flat mucosae and this, together with the greater number of crypt columns, indicates a five or sixfold increase in cell production rate per crypt. A similar increase has been demonstrated indirectly by measuring the DNA content of intestinal washings (Pink et al, 1970) but a direct comparison would involve estimation of any changes in actual numbers of crypts in the entire small bowel in coeliac disease. The present data further suggest that differences exist in mucosal kinetics in the several gluten-sensitive enteropathy syndromes studied. It would appear that the increase in cell production rate is smaller in childhood coeliac disease than in the two adult groups; between adult coeliac disease and dermatitis herpetiformis there seems to be little difference. Our study has shown some minor changes in the mitotic index of the stem cell compartments and in the sizes of the other kinetic compartments. It should, however, be noted that the increases in cell production rate are very similar.

Corroborative evidence for these conclusions has come from the work of Trier and Browning (1970); studying small bowel mucosa maintained in organ culture, they demonstrated that in biopsies from patients with adult coeliac disease increased numbers of crypt cells became labelled on exposure to tritiated thymidine. An increased rate of cell migration was also shown. However, short-term kinetic studies performed in organ culture may be complicated by the apparent dissociation of rates of entry into mitosis and into DNA synthesis, possibly as a consequence of explantation (Simnett, 1971).

Some workers have suggested that one source of difficulty inherent in any morphometric study of small bowel mucosa is the definition of the cryptvillus junction. In practice we have not found this to be important, and in any event the large number of crypts analysed compensates for any minor variation in interpretation. A further difficulty is in the choice of controls. A random normal population cannot readily be defined (Baker, 1972) and obviously could not be biopsied. What have been compared here are basically the kinetic differences between villous and avillous mucosae.

To summarize our findings, therefore, we conclude that in the flat mucosa of coeliac disease there is a large increase in cell production rate per crypt. There is also a three-dimensional increase in crypt size, and we propose that these morphological appearances are the result of a hyper-proliferative mucosal adaptation to the need for an augmented cell production rate, namely, the necessity to accommodate the required large numbers of proliferating cells.

There is in these results an apparent anomaly from which a prediction can be made. It will be noted from tables IV and II that in adult coeliac disease there is a sixfold increase in cell production rate, but only a threefold increase in the numbers of proliferating cells. The cells within the proliferative compartment may be dividing faster; that is, there may be a decrease in the cell cycle time, $T_{c}$ (the interval between two succeeding divisions of a cell). The mitotic index is almost doubled in adult coeliac disease (table III), and this is related to the cell cycle time thus: 


$$
I_{m}=\frac{t_{m}}{T_{c}}
$$

The increase in mitotic index could be due to a marked prolongation in the duration of mitosis; we consider this unlikely and anticipate instead a reduction in the cell cycle time in the flat mucosa of gluten-sensitive enteropathy.

We are grateful to Professor A. G. Heppleston for continued encouragement and advice. Miss E. Robinson rendered skilled technical assistance. This work was supported by the North of England branch of the Cancer Campaign.

\section{References}

Baker, S. J. (1972). In Proceedings of the XIth Conference of the International Society of Geographical Pathology, Newcastle-uponTyne.

Bertalanffy, F. D., and Nagy, K. P. (1961). Mitotic activity and renewal rate of the epithelial cells of human duodenum. Acta anat. (Basel), 45, 362-370.

Booth, C. C. (1970). Enterocyte in coeliac disease. Brit. med. J., 3, 725731.

Cairnie, A. B., Lamerton, L. F., and Steel, G. G. (1965a). Cell proliferation studies in the intestinal epithelium of the rat. I. Determination of the kinetic parameters. Exp. Cell Res., 39, 528-538.

Cairnie, A. B., Lamerton, L. F., and Steel, G. G. (1965b). Cell proliferation studies in the intestinal epithelium of the rat. II Theoretical aspects. Exp. Cell Res., 39, 539-553.

Cairnie, A. B., and Bentley, R. E. (1967). Cell proliferation studies in the intestinal epithelium of the rat. Hyperplasia during lactation. Exp. Cell Res., 46, 428-440.
Cleaver, J. E. (1967). Thymidine Metabolism and Cell Kinetics. NorthHolland Publishing Co., Amsterdam.

Creamer, B. (1962). Dynamics of the mucosa of the small intestine in idiopathic steatorrhoea. Gut, 3, 295-300.

Lamerton, L. F. (1972). Cell proliferation and the differential response of normal and malignant tissues. Brit. $J$. Radiol., 45, 161-172.

Lipkin, M. (1965). Cell replication in the gastrointestinal tract of man. Gastroenterology, 48, 616-624.

Padykula, H. A., Strauss, E. W., Ladman, A. J., and Gardner, E. H. (1961). A morphologic and histochemical analysis of the human jejunal epithelium in nontropical sprue. Gastroenterology, 40, 735-765.

Pink, I. J., Croft, D. N., and Creamer, B. (1970). Cell loss from small intestinal mucosa: a morphological study. Gut, 11, 217-222.

Sigdestad, C. P., Bauman, J., and Lesher, S. W. (1969). Diurnal fluctuations in the number of cells in mitosis and DNA synthesis in the jejunum of the mouse. Exp. Cell Res., 58, 159-162.

Simnett, J. D. (1971). Reduplication of DNA content in nuclei from organ cultures of mouse lung. Neoplasma, 19, 11-18.

Trier, J. S., and Browining, T. H. (1970). Epithelial cell renewal in cultured duodenal biopsies in celiac sprue. New Engl. J. Med., 283, 1245-1250.

Wimber, D. R., and Lamerton, L. F. (1963). Cell population studies in the intestine of continuously irradiated rats. Radiat. Res., 18, 137-146.

Wright, N. A., Morley, A. R., and Appleton, D. R. (1972a). The effect of testosterone on cell proliferation and differentiation in the small bowel. J. Endocr., 52, 161-175.

Wright, N. A., Morley, A. R., and Appleton, D. R. (1972b). Variation in the duration of mitosisin the crypts of Lieberkühn of the rat; a cytokinetic study using vincristine. Cell Tiss. Kinet., 5, 351-364.

Wright, N. A., Watson, A. J., Morley, A. R., Appleton, D. R., Marks, J. M., and Douglas, A. (1973). The cell cycle time in flat (avillous) mucosa of the human small intestine. Gut, 14,

Yardley, J. H., Bayless, T. M., Norton, J. H., and Hendrix, T. R. (1962). Celiac disease: a study of the jejunal epithelium before and after a gluten free diet. New Engl.J. Med., 267, 1173-1179. 